Ultrasound

2016, Vol. 24(4) 188

\title{
A thank you to our retiring Editor-in-Chief
}

(C) The Author(s) 2016

Reprints and permissions:

sagepub.co.uk/journalsPermissions.nav

DOI: $10.1177 / 1742271 X 16676167$

ult.sagepub.com

@SAGE

Dr Kevin Martin took over the role of Editor-in-Chief of the BMUS journal, Ultrasound, in 2013 and has worked tirelessly to raise the profile and quality of the journal during his two terms as Editor. His initial term as Editor coincided with his retirement as Head of Instrumentation at University Hospitals of Leicester NHS Trust, and it was always easy to imagine him editing journal articles from exotic locations as he indulged his passions in sailing and exploring new destinations.

Although Kevin has had the help and support of deputy editors and the editorial board, his lifetime experience and knowledge in ultrasound has enabled him to steer the course of the journal through times which may have appeared to more faint-hearted editors, as perilously close to disaster. However with his steady hand on the tiller, Ultrasound enjoyed several major achievements under his tenure including having Ultrasound indexed in PubMed Central and the Emerging Sources Citation Index (ESCI), the launch of the Journal's online Continuing Medical Education training tools, and the revitalised cover and internal layout. He has published special issues on 'Contrast Enhanced Ultrasound', 'Education and Training in Ultrasound', and 'Quality Assurance'. Many of the papers in these special issues are the most cited papers of the journal.

BMUS is greatly indebted to Kevin for his many years of service, which not only include his activities as journal Editor-in-Chief for the past four years but also as President of the Society from 2006 to 2008. On behalf of BMUS, we thank Kevin for his efforts for this dedication to the journal and to the Society.

$$
\text { Carmel M. Moran }
$$

Carmel M Moran (President of BMUS)

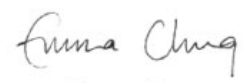

Emma Chung (Honorary Secretary of BMUS)

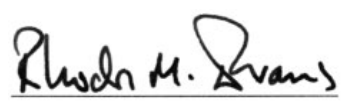

Rhodri Evans (Honorary Treasurer of BMUS)

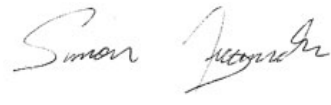

Simon Freeman (President-elect of BMUS)

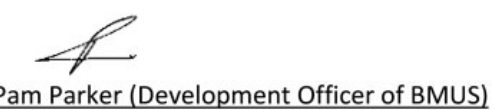

